\title{
Evaluating uncertainty in climate change impacts on crop productivity in the Iberian Peninsula
}

\author{
M. Ruiz-Ramos ${ }^{1, *}$, M. I. Mínguez ${ }^{2}$ \\ ${ }^{1}$ Instituto de Ciencias Ambientales de la Universidad de Castilla La Mancha, Avda. Carlos III s/n, 45071 Toledo, Spain \\ ${ }^{2}$ Agricultural Systems Group, Depto. Producción Vegetal: Fitotecnia, E.T.S. Ingenieros Agrónomos, \\ Universidad Politécnica de Madrid, Avda. Complutense s/n, 28040 Madrid, Spain
}

\begin{abstract}
Using a multi-model ensemble of climate-change impacts over the Iberian Peninsula, we identified regions and cropping options for which the uncertainty levels of projected impacts on crop productivity were either high or low. The ensemble consisted of 10 members per combination of scenario, climate model, location and cropping option, and was used to quantify the uncertainty of impacts on crop yield. CERES wheat and maize simulation models were linked to the control run and 1 scenario provided by 10 regional climate models (RCMs): control (1969-1990) and A2 future (2070-2100) climate. The contribution of RCMs, locations and cropping options to uncertainty on yield projections was analysed. Differences between the sign of the response and $30 \mathrm{yr}$ time series of projections generated by each member of the ensemble were compared. The largest response to A2 scenarios also resulted in the smallest uncertainty, and vice versa. Low uncertainty was found for the sign of the yield response, which was mainly positive for spring and winter cropping options and negative for the summer option. Uncertainty was lower for A2 than for control projections. Uncertainty was largest in northern, coastal and mountain regions, and smallest for inland southern regions, and depended on seasonal cropping options. Minimum and maximum uncertainty were found for maize and irrigated spring wheat, respectively. Water availability was the determinant for interannual variability and its uncertainty. Choice of RCM contributed less to uncertainty than choice of location, and choice of cropping option contributed more to uncertainty than both of these factors. Interannual variability showed larger uncertainty than mean impact magnitude, and this uncertainty was larger than that of the sign of the yield response. Regions with high uncertainty could benefit from higher-resolution simulations.
\end{abstract}

KEY WORDS: Climate change impact - Ensemble of projections - Uncertainty - Wheat and maize yield · Interannual variability

\section{INTRODUCTION}

Impacts of climate change on crop productivity can be projected by evaluating the outputs from crop simulation models when run with control climate and climate change scenarios from climate models (Easterling et al. 2007). Crop models simulate daily interactions with climate, soils and management that determine growth, development and yield (productivity) of individual crops (Loomis \& Connor 1996, Tubiello \& Ewert 2002). Climate models, and in particular regional climate models (RCMs) nested in atmosphereocean coupled general circulation models (AOGCMs) of lower resolution, provide the necessary driving climatic variables of solar radiation, temperature, rainfall, pressure water vapour and wind run, at several geographic scales (Carbone et al. 2003, Mearns 2003, Mearns et al. 2003). RCMs provide climate data at high resolution (e.g. $50 \times 50 \mathrm{~km})$, that can account for topographic variability (Castro et al. 1995), which is an important determinant of crop productivity in regions such as the Iberian Peninsula (Guereña et al. 2001).

Simulations over a number of years with a single configuration of this modelling chain (AOGCMRCM-Crop model) provide information on interannual variability of the projections. Evaluation of uncertain- 
ties can only be made when outcomes of various modelling configurations are compared, as for instance by Déqué et al. (2007). The range of projections from the various modelling options provides data for evaluating and measuring uncertainty. The use of ensembles of projections is spreading from climate modelling to impact assessment because they provide many impact projections, as many as the number of 'ensemble members' i.e. [AOGCM-RCM-Crop model] modelling configurations. The number of ensemble members increases when impacts are simulated by different models or methods, or under different hypotheses. Quantification of uncertainty and the relative importance of its sources is a major step to improve interpretation of impacts and resultant decisions on adaptation strategies.

Uncertainty is incorporated along the entire modelling chain. Impact analyses obtained from the modelling chain (AOGCM-RCM-Crop/impact model) are dependent on the climate and crop model themselves and how they are combined for analysis. In that case, uncertainty has 3 main sources: (1) climate modelling, (2) crop modelling and (3) the connections between them. For (1), this includes the definition of future scenarios, downscaling methods applied (Christensen et al. 2007) and resolution of the climate projections themselves (Giorgi et al. 2001). Within dynamic downscaling, high-resolution climate models (i.e. RCMs), aggregate uncertainty by sampling over the simulated period (Déqué et al. 2007), by the boundary forcings and parameterisation, and finally by the number of models and criteria for building the ensemble. For (2), uncertainty is introduced by the crop models' approach and description of crop growth, development, etc., and in particular the simulation of processes such as the effects of $\left[\mathrm{CO}_{2}\right]$ on photosynthetic rates and water use, together with the combined effects of temperature rise on crop development and growth (Kimball et al. 2002, Asseng et al. 2004, Ainsworth \& Long 2005, Ainsworth et al. 2008). Other sources of uncertainty are the number of crop models, the cropping options (crop type, growing season, management), the input data (soil and field data) and the up-scaling of results. For (3), uncertainty arises from how users connect the information flow from climate to impact models, for instance by selecting the 'delta of climate' or 'direct use' methods (examples in Mínguez et al. 2004, Olesen et. al 2007). The 'delta of climate' method applies monthly changes between simulated future and control climates to the observed climate for building an operative future scenario, assuming that the relationships between climate variables for the present climate remain unchanged in the future under climate change conditions. 'Direct use', which implies that both the control run and the future scenario are applied directly to impact models, does not assume this hypothesis. However, with this method it is advisable to use as output the relative change of the impact variable, i.e. 'delta of impact', instead of the absolute value of the control run or scenario projections, since the goodness of the control run of climate varies spatially and from one RCM to another. Another linkage technique to manage uncertainty is found in the construction of impact response surfaces, as has been applied to crop production (van Minnen et al. 2000). These and other methods used to translate probabilistic methodology to impact assessment have been discussed by Carter et al. (2007).

In practice, the construction of an ensemble including all methods mentioned above is currently not feasible. For this reason, to separate uncertainty into its constituent elements, 1 option is to analyse specific uncertainty sources with partial ensembles. In previous studies on the Iberian Peninsula (Table 1), Mínguez et al. (2007) and Olesen et al. (2007) analysed climate change impacts on crop production by combining crop simulation models with climate change projections from $10 \mathrm{RCMs}$ generated in the EU project PRUDENCE.

Olesen et al. (2007) compared results obtained for northern and southern Europe. While the main response in the north was expansion of suitable cropping areas, that of the south was small increases or decreases in the yield of some crops. The authors proposed that an increase in the yield of autumn-sown spring wheat in Spain could be used as an indicator of seasonal change. In another study, Mínguez et al. (2007) compared simulated yields of wheat and maize over 30 yr periods of control (1960-1990) versus future (2070-2100) climates. They identified areas above $600 \mathrm{~m}$ above sea level (a.s.l.) in southern Europe as locations with the greatest probability of a positive effect for autumn-sown crops. On the other hand, studies using aggregated agricultural productivity reported a dominant decrease of yield for several crops in Spain (Iglesias et al. 2009).

Management also plays an important role in the determination of uncertainty. Mínguez et al. (2007), for instance, showed how irrigation of autumn-sown wheat changed uncertainty levels generated by rainfall projections. However, in that work, uncertainty analysis was limited to standard deviation of means of 10 RCM-driven projections for each location. Time series were not compared, and decomposition and quantification of possible sources of uncertainty were not attempted.

Another example of a multi-model ensemble applied to agriculture is a study by Semenov \& Stratonovitch (2010). There, the AR4 multi-model ensemble of GCMs in combination with the weather generator LARS-WG 
Table 1. Summary of the analyses undertaken in our previous and current work. GCM: general circulation model; RCM: regional climate model; NEM: number of ensemble members projecting the same sign of impact; C: control; A2: future scenario (2070-2100)

\begin{tabular}{|c|c|c|c|c|c|c|}
\hline & $\begin{array}{l}\text { Guereña et al. } \\
(2001)\end{array}$ & $\begin{array}{l}\text { Mínguez et al. } \\
(2004,2007)_{i} \\
\text { Olesen et al. (2007) }\end{array}$ & \multicolumn{4}{|c|}{ - Current work - } \\
\hline Climate models & $1 \mathrm{GCM}, 1 \mathrm{RCM}$ & $10 \mathrm{RCMs}$ & \multicolumn{4}{|c|}{$10 \mathrm{RCMs}$} \\
\hline $\begin{array}{l}\text { Simulated crops } \\
\text { (CERES model) }\end{array}$ & $\begin{array}{l}\text { Winter wheat, } \\
\text { barley, maize }\end{array}$ & $\begin{array}{l}\text { Winter and spring } \\
\text { wheat, maize }\end{array}$ & \multicolumn{4}{|c|}{$\begin{array}{l}\text { Cropping options: } \\
\text { Winter and spring wheat (rainfed and irrigated), irrigated maize }\end{array}$} \\
\hline $\begin{array}{l}\text { Objective of the } \\
\text { analysis }\end{array}$ & $\begin{array}{l}\text { Impact simulation, } \\
\text { test GCMs vs. } \\
\text { RCMs }\end{array}$ & $\begin{array}{l}\text { Impact simulation } \\
\text { and coarse } \\
\text { uncertainty }\end{array}$ & $\begin{array}{l}\text { Response to } \\
\text { A2 scenarios }\end{array}$ & $\begin{array}{l}\text { Uncertainty } \\
\text { Sign of impact }\end{array}$ & $\begin{array}{l}\text { measurement and de } \\
\text { Magnitude of } \\
\text { impact }\end{array}$ & $\begin{array}{l}\text { ecomposition } \\
\text { Interannual } \\
\text { variability of impact }\end{array}$ \\
\hline $\begin{array}{l}\text { Analysis } \\
\text { technique }\end{array}$ & $\begin{array}{l}\text { Crop simulation } \\
\text { and GIS }\end{array}$ & $\begin{array}{l}\text { Crop simulation } \\
\text { and GIS, CV, SD }\end{array}$ & $\begin{array}{l}\text { Statistical com- } \\
\text { parison of means }\end{array}$ & GIS analysis & $\begin{array}{l}\text { Statistical com- } \\
\text { parison of means }\end{array}$ & $\mathrm{CV}$ of time series \\
\hline Indicator & Yield & Yield CV, SD & $\begin{array}{l}\text { Degree of } \\
\text { discrimination }\end{array}$ & Yield and NEM & $\begin{array}{l}\text { Degree of } \\
\text { coincidence }\end{array}$ & $\begin{array}{l}\text { Mean CV, } \\
\text { (CVmax-CVmin) }\end{array}$ \\
\hline Spatial domain & Iberia & $\begin{array}{l}\text { Iberian agricultural } \\
\text { area and } 12 \text { locations }\end{array}$ & 12 locations & $\begin{array}{l}\text { Iberian agri- } \\
\text { cultural area }\end{array}$ & 12 locations & 12 locations \\
\hline Data used & Mean of $30 \mathrm{yr}$ & Mean of $30 \mathrm{yr}$ & $30 \mathrm{yr}$ time series & Mean of $30 \mathrm{yr}$ & 30 yr time series & 30 yr time series \\
\hline $\begin{array}{l}\text { Simulations } \\
\text { compared }\end{array}$ & $\begin{array}{l}\text { Qualitative } \\
\text { comparison of } \\
\text { simulations }\end{array}$ & $\begin{array}{l}\text { Qualitative of com- } \\
\text { parison simulations } \\
\text { and CV among RCMs }\end{array}$ & $\begin{array}{l}\mathrm{C} \text { vs. } \mathrm{A} 2 \text { of } \\
10 \text { ensemble } \\
\text { members }\end{array}$ & $\begin{array}{l}\mathrm{C} \text { vs. } \mathrm{A} 2 \text { of } \\
10 \text { ensemble } \\
\text { members }\end{array}$ & $\begin{array}{l}\text {-C runs among } \\
\text { ensemble members } \\
\text {-A2 scenarios } \\
\text { among ensemble } \\
\text { members }\end{array}$ & $\begin{array}{l}\text {-C runs among } \\
\text { ensemble members } \\
\text {-A2 scenarios } \\
\text { among ensemble } \\
\text { members }\end{array}$ \\
\hline $\begin{array}{l}\text { Criteria for } \\
\text { clustering } \\
\text { results }\end{array}$ & Crops & $\begin{array}{l}\text { Crop location } \\
\text { management }\end{array}$ & $\begin{array}{l}\text { RCM cropping } \\
\text { option, location } \\
\text { management }\end{array}$ & $\begin{array}{l}\text { Cropping } \\
\text { option }\end{array}$ & $\begin{array}{l}\text { Cropping option, } \\
\text { location } \\
\text { management } \\
\text { scenario }\end{array}$ & $\begin{array}{l}\text { Cropping option, } \\
\text { location } \\
\text { management } \\
\text { scenario }\end{array}$ \\
\hline
\end{tabular}

(Semenov 2007) and the Sirius (Jamieson et al. 1998) crop model was used to assess the probability of heat stress during anthesis of wheat in several locations around Europe. Probability increased less for Mediterranean than for northern and central locations, probably because wheat reached anthesis earlier in the Mediterranean region than in more northern locations. Cai et al. (2009) also used the AR4 multi-model ensemble of GCMs to assess the impact of climate change on maize yield and soil water balance in Illinois (USA). They found an increased probability of yield reduction and soil water deficit during the maize growing season, and discussed the weighing of members within an ensemble as a method to avoid overestimation of uncertainty.

Here we used the multi-model ensemble generated in the European project PRUDENCE. We evaluated the uncertainty of climate change impacts on the productivity of summer (maize) and winter (wheat) crops under various regimes on the Iberia Peninsula using a single model for each crop. One objective was to measure uncertainty in projections of impact arising from interactions between the RCM output and process simulations within the crop model. We focused on factors from the impact assessment that aggregate or reveal uncertainty, i.e. crop-cultivar-management combinations, or 'cropping options', and location, and we ana- lysed the influence of climate assessment factors as RCMs. This identifies cropping options that can be predicted with the least amount of uncertainty. A second objective was to identify areas and understand cases where projection quality needs improvement. For this purpose, 2 related aspects were important in this study: the decomposition and quantification of uncertainty.

\section{METHODS}

Table 1 summarises the analyses undertaken and the data used in the present work, and compares these to previous studies on the Iberian Peninsula. The construction of the ensemble and analyses are described below in detail.

\subsection{Multi-model ensemble of climate and impact projections}

Climate scenarios were generated by 10 RCMs from PRUDENCE, run at a resolution of $50 \times 50 \mathrm{~km}$ horizontal grid: HIRHAM, PROMES, RegCM, ARPEGE, CHRM, CLM, RCAO, REMO, RACMO and HadRM3H. Eight RCMs were nested in the HadAM3H while 2 RCMs, 
ARPEGE and RCAO, used the boundary conditions of the AOGCMs ARPĖGE/OPA and ECHAM/OPYC4, respectively. These AOCGMs and RCMs have been constructed by European research groups on climate change and have been described extensively by Christensen \& Christensen (2007). Two periods were considered: control (1969-1990) and future (2070-2100) climate or A2, which corresponds to $635-856 \mathrm{ppm} \mathrm{CO}_{2}$ from 2070-2100 future greenhouse gas emissions (Nakicenovic \& Swart 2000).

The climate data were used to build a multi-model ensemble of first-order impacts on Iberian Peninsula cropping systems. A complete description of the methodology used for these simulations and preliminary results can be found in Guereña et al. (2001), Mínguez et al. $(2004,2007)$ and Olesen et al. (2007). Briefly, CERES wheat and maize models (Ritchie \& Otter 1985, Jones \& Kiniry 1986, within the DSSAT 3.5 frame, Tsuji et al. 1994), previously calibrated for various Iberian locations (Mariscal 1993, Rebollo 1993, Iglesias \& Mínguez 1995, Quemada et al. 1997, LópezCedrón et al. 2005), were used to perform simulations for the control period and the A2 scenario using daily outputs from RCMs. Maximum and minimum temperature, solar radiation, precipitation, wind speed and relative humidity at surface level were formatted according to weather files of the crop models, thus applying the 'direct use' method. Outputs from the crop simulation were then used to calculate relative changes in yield, i.e. 'delta of impact'. Simulations were run for land suitable for agriculture today, including 12 locations chosen from representative agricultural regions that differ in growing conditions and cropping systems (Mínguez et al. 2007). Two wheat cultivars differing in vernalisation requirement (i.e. low temperatures are needed to induce flowering) were included: winter wheat sown in mid-October and spring wheat in late November (with no vernalisation requirements), both under rainfed and irrigated conditions (Table 2). Winter wheat was simulated only where the vernalisation requirements are currently fulfilled. Maize was only simulated with irrigation and was sown in late March, April and May in southern, central and northern regions, respectively (Table 2). This choice of crops and sowing dates allowed comparison between winter and summer growing seasons. Adaptation was not investigated here, so sowing dates and cultivars were the same for control and future (A2) climate simulations.

In summary, by connecting 1 crop model to 10 RCMs, we worked with the 10 -member ensemble for each cropping option-location scenario. Crop yield was used as an aggregated indicator for establishing ranges of uncertainty and detecting locations, and cropping options with maximum or minimum uncertainty associated with the projections.

\subsection{Response to $\mathrm{A} 2$ climate scenario}

A statistical test for comparison of mean crop yields of each $30 \mathrm{yr}$ time series was applied using SPSS software, between the control run and the A2 scenario for each simulation combination for 12 locations chosen from representative agricultural regions that differ in growing conditions and cropping systems (Fig. 1).

The comparisons comprised 960 simulation combinations that arose from the $10 \mathrm{RCMs}, 2$ scenarios, 6 to 12 locations and the following 5 major cropping options: rainfed or irrigated winter wheat, rainfed or irrigated spring wheat and irrigated summer maize. Winter wheat was only analysed for 6 locations in the north-central regions. Two locations, S-Valley 1 and S-Valley 2 (Córdoba), shared all input data except soil type, which differed in depth and texture. S-Valley 1 was a sandy Xerorthent $0.80 \mathrm{~m}$ deep, and S-Valley 2 was a clayey $1.5 \mathrm{~m}$ choromoxerert.

The results were clustered according to cropping option, location and RCM. The degree of discrimination between control and A2, measured by the percentage of significant differences between time series projections for both, was computed for each cluster.

Table 2. Crops, cultivar, area of cultivation, growing season, sowing dates, management (none of the options are N-limited) and specific features used for simulation of impacts. IP: Iberian Peninsula (suitable areas according to altitude and soil)

\begin{tabular}{|c|c|c|c|c|c|c|}
\hline Crop & Cultivar & $\begin{array}{l}\text { Cultivation } \\
\text { area }\end{array}$ & Growing season & Sowing date & Management & Specific features \\
\hline \multirow[t]{2}{*}{ Wheat } & Winter & $\begin{array}{l}\text { North and } \\
\text { centre of IP }\end{array}$ & Autumn-winter-spring & 10 October & Rainfed and irrigated & $\begin{array}{l}\text { Vernalisation } \\
\text { requirements }\end{array}$ \\
\hline & Spring & Whole IP & Autumn-winter-spring & 10 November & Rainfed and irrigated & - \\
\hline Maize & FAO Cycle 700 & Whole IP & Late spring-summer & $\begin{array}{l}\text { Northern IP: } 16 \text { May } \\
\text { Central IP: } 16 \text { April } \\
\text { Southern IP: } 30 \text { March }\end{array}$ & Irrigated & - \\
\hline
\end{tabular}




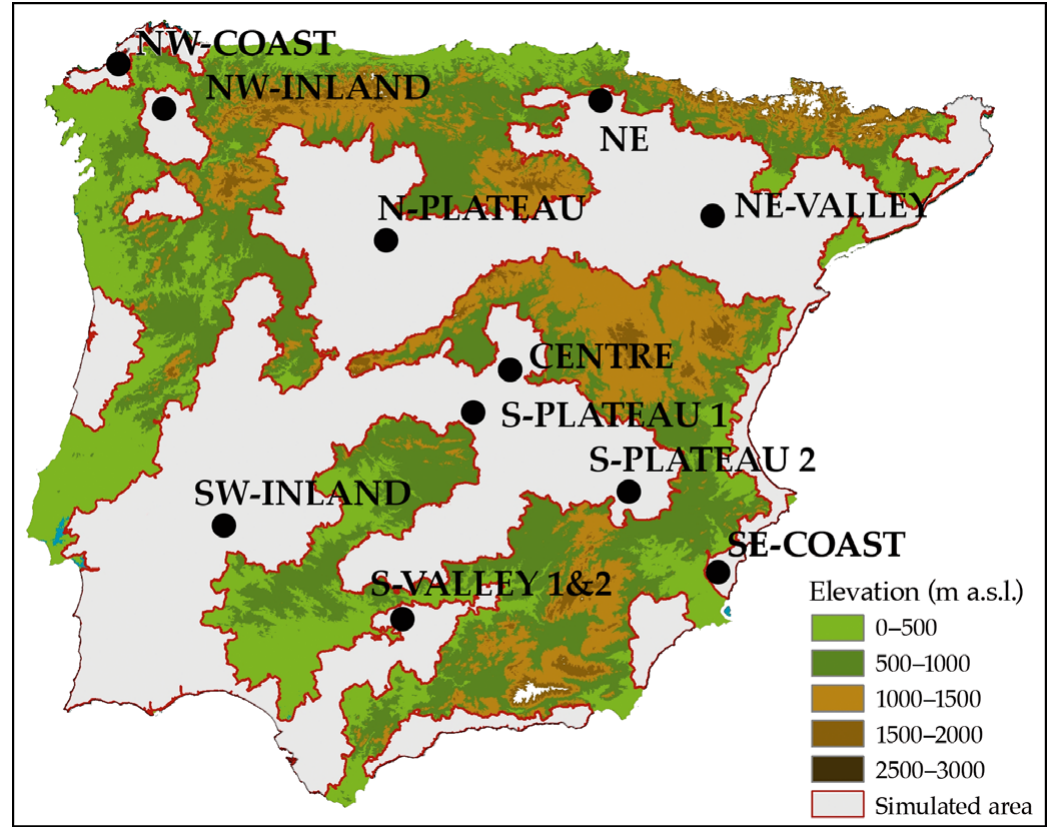

Fig. 1. Simulated areas and altitude in the surrounding areas in the Iberian Peninsula. Locations chosen from representative agricultural regions that differ in growing conditions and cropping systems. Altitude of NW- and SE-Coast regions is below $50 \mathrm{~m}$ above sea level (a.s.l.); SW-Inland, NE-Valley and S-Valley 1 and 2 are between 100 and $250 \mathrm{~m}$ a.s.l.; NW-Inland and NE are between 450 and $500 \mathrm{~m}$ a.s.l. and close to mountain areas; N-Plateau, Centre and S-Plateau 1 and 2 are between 550 and $700 \mathrm{~m}$ a.s.l. Locations 1 and 2 in S-Valley only differed in soil type
The $30 \mathrm{yr}$ time series of yield projections for the 12 representative locations were then statistically compared using SPSS software, in 2 analyses:

(1) Comparison of means: For each scenario-RCM-cropping option, 30 yr yield series were compared 2 by 2 with the other 9 members with the same combination. The Games-Howell test was selected since the hypothesis of variance homogeneity was not always fulfilled (Sheskin 2004, Field 2005). From these tests, the degree of coincidence among ensemble members was measured by the percentage of pairs showing a non-significant difference, at the 0.05 level of significance. A large degree of coincidence is associated with small uncertainty and vice versa. Locations and ensemble members showing the largest and smallest degree of coincidence were identified.

(2) Comparison of interannual variability: This was estimated for each time series from its coefficient of variation (CV). Means and ranges (CVmaxCVmin) were then calculated for the 10 members of each scenarioRCM-cropping option combination. Mean CV estimates averaged the

\subsection{Uncertainty measurement and decomposition}

Uncertainty of crop yield projections was analysed in 3 ways. First, the sign of the impact on crop yield (increase or no difference versus decrease in yield) was selected. Instead of specific locations, simulations were made for agricultural areas (Fig. 1) that were identified according to soil characteristics. The coincidence among the ensemble members is presented as maps showing areas where projections of 0 to $10 \mathrm{RCMs}$ produced the same sign of yield response. These maps identify areas of maximum and minimum uncertainty of cropping options (crop-cultivar-management combination), and provide spatial comparison of results. For interpretation of these results, we defined a projection of 'low uncertainty' when at least 9 members of the 10-member ensemble held the same sign of response of crop yield, 'medium uncertainty' when 7 or 8 members were in agreement, and 'high uncertainty' when only 5 or 6 members agreed. In these maps, low uncertainty is fulfilled by items 1, 2, 9 and 10 in the legend. Medium uncertainty includes items 3, 4, 7 and 8. High uncertainty implies that ca. half of the members projected 1 sign of response and the remainder the opposite, i.e. items 5 and 6. interannual variability of each combination (a larger mean CV indicates greater interannual variability) and is not per se a measure of uncertainty; the range (CVmax-CVmin) reflects uncertainty generated in the estimation of interannual variability: a wider range indicates greater uncertainty.

\section{RESULTS}

The values of crop yield obtained for control runs and future scenarios were presented by Mínguez et al. $(2004,2007$, where control runs were compared to ERA-15 [Gibson et al. 1999] driven simulations), although irrigation simulations were improved for the current work. The range of yields from control runs was ca. 9000 to $13000 \mathrm{~kg} \mathrm{ha}^{-1}$ for irrigated maize, 3000 to $6000 \mathrm{~kg} \mathrm{ha}^{-1}$ for rainfed winter wheat, 4000 to $11000 \mathrm{~kg} \mathrm{ha}^{-1}$ for irrigated winter wheat, 2000 to $4000 \mathrm{~kg} \mathrm{ha}^{-1}$ for rainfed spring wheat and 5000 to $10000 \mathrm{~kg} \mathrm{ha}^{-1}$ for irrigated spring wheat. All cropping options, locations and RCMs showed outliers, illustrating the need for using an ensemble of models. Therefore, the following analyses focus on the uncertainty of these impacts. 


\subsection{Response to A2 climate scenarios}

This section analyses climate scenarios as sources of uncertainty, and the main causal factor is the difference in climate change simulated by individual RCMs. The degree of discrimination between control and A2 yield projections is summarised in Table 3 and pre-

Table 3. Summary of mean values and difference between maximum and minimum values (referred to as 'range') of the uncertainty indicators: degree of discrimination between control run and A2 future scenario, degree of coincidence among projections of each regional climate model (RCM)-scenario-location-

cropping option combination, and (CVmax-CVmin) of yield projections

\begin{tabular}{|lccccc|}
\hline & Mean & $\begin{array}{c}\text { Total } \\
\text { range }\end{array}$ & $\begin{array}{c}\text { Range } \\
\text { among } \\
\text { locations }\end{array}$ & $\begin{array}{c}\text { Range among } \\
\text { cropping } \\
\text { options }\end{array}$ & $\begin{array}{c}\text { Range } \\
\text { among } \\
\text { RCMs }\end{array}$ \\
\hline $\begin{array}{l}\text { Degree of } \\
\text { discrimination }\end{array}$ & 50 & $0-100$ & $30-63$ & $24-95$ & $41-61$ \\
$\begin{array}{c}\text { Degree of } \\
\text { coincidence }\end{array}$ & 39 & $7-84$ & $30-50$ & $24-57$ & - \\
$(\mathrm{CVmax}-\mathrm{CVmin})$ & 41.2 & $4-227$ & $23-51$ & $9-91$ & - \\
\hline
\end{tabular}

Table 4. Response to A2 scenarios of yield projections measured by the degree of discrimination between the control run and the A2 future scenario. Discrimination was clustered by cropping option for every location and regional climate model (RCM)

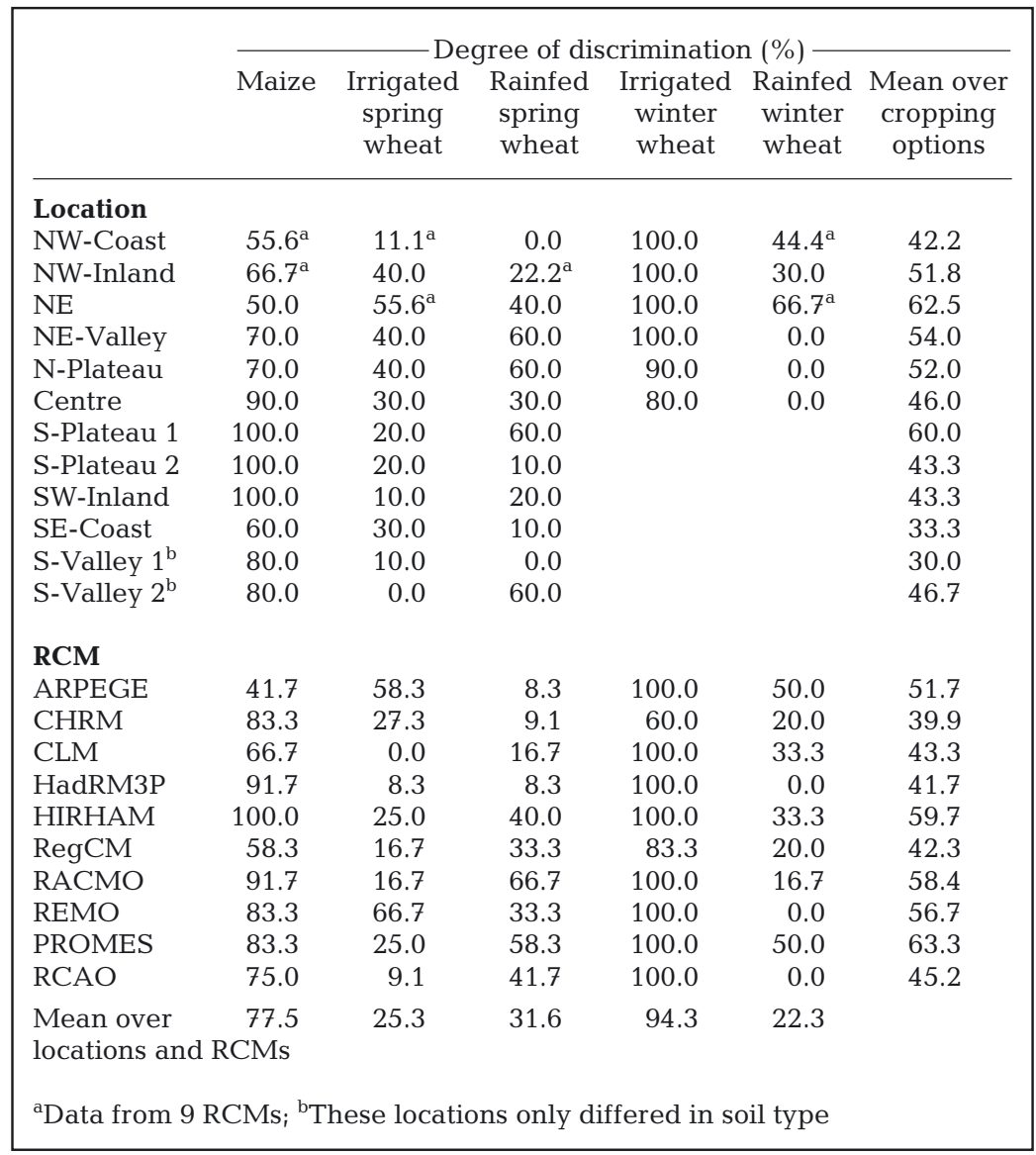

sented by location and by RCM in Table 4. Discriminaranged from 0 to $100 \%$ for individual combina-

A full response (discrimination $=100 \%, 10$ out of 10 RCMs with significant differences) was obtained for irrigated winter wheat in the north, and for maize in the southern plateau. No response (discrimination $=0 \%, 0$ out of $10 \mathrm{RCMs}$ ) was found for rainfed winter wheat in the central and northern plateaus. There were no significant differences in yield projections between control and future climate in those areas and for this cropping option.

Irrigated cropping options showed a larger response to A2 scenarios (either a significant increase or decrease in yield) except for irrigated spring wheat, with a range of discrimination among cropping options from 22 to $95 \%$ (Table 4).

The sites showing the largest response were located in the north-east and centre, while locations showing the smallest response were in the south-east and south, with a range from 30 to $63 \%$ (Table 4 ). The response between RCMs varied in a similar range from $40 \%$ for the CHRM climate model to $63 \%$ for the PROMES climate model (Table 4). RCMs driven by different AOGCMs than the other ensemble members showed a response to A2 in the range found for the other RCMs nested in the AOGCM HadAM3H.

\subsection{Uncertainty in the sign of the crop yield response}

This section analyses coincidence in the sign of the response (increase or decrease) of crop yield as an indicator of uncertainty resulting from the causal factor location-cropping option combination. Impact uncertainty was low for the summer cropping options represented by irrigated maize. The analysis projects a yield decrease with low uncertainty on ca. $80 \%$ of the simulated area (Fig. 2a). Yield increase was only projected for northern areas with medium uncertainty. Areas of maxi- 


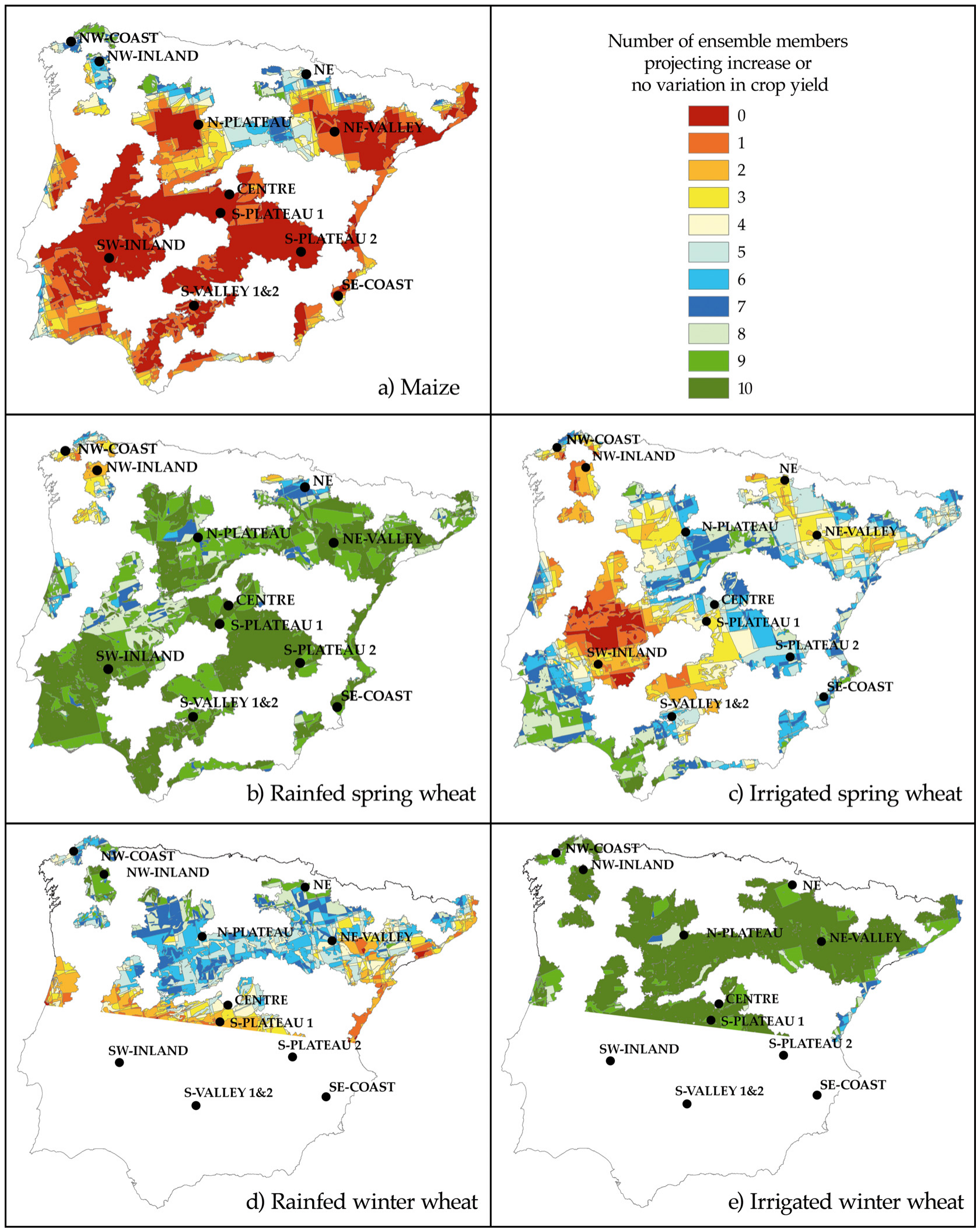

Fig. 2. Coincidences among the 10 ensemble members on sign of impact on crop yield for (a) maize, (b) rainfed spring wheat, (c) irrigated spring wheat, (d) rainfed winter wheat and (e) irrigated winter wheat. Items at the extremes of the legend, i.e. red and green, are areas of low uncertainty, as all members agree in the impact sign projection. Red represents agreement in decreasing yield, while green indicates agreement in increasing yield. Blue and yellow correspond to areas where both negative and positive changes in crop yield are projected by some members, i.e. medium to high uncertainty areas 
mum uncertainty were found in the coastal regions and in northern areas close to mountains, e.g. in the Duero Valley. The outcome was more complex for autumnsown crops, i.e. grown during autumn, winter and spring.

The sign of the impact on the yield of rainfed spring wheat was assessed with low uncertainty on ca. $90 \%$ of the simulated area (Fig. 2b) and with a projected yield increase. Areas of medium uncertainty were found in the north and north-west (Galicia).

Results differed for irrigated spring wheat for which medium to high uncertainty was found in ca. $80 \%$ of the simulated area (Fig. 2c). Regions of low uncertainty were located in the west, with a projected yield increase in the south-west and a decrease in the remaining western regions. Considering the whole peninsula, less than one-third of the simulated area showed increases in yield, in contrast to results with rainfed spring wheat. Regions of maximum uncertainty were located in the north-east (Ebro Valley) and centre, where areas of increasing and decreasing yields were adjacent. Positive impacts dominated in coastal areas.

Responses of rainfed winter wheat differed from those of rainfed spring wheat. The sign of impact was assessed with medium to high uncertainty (Fig. 2d). Projections of low uncertainty were obtained only for ca. $5 \%$ of the area. A projected yield increase dominated the north of the simulated area, while a yield decrease was projected in the centre.

A yield increase was projected for irrigated winter wheat across all simulated areas with low uncertainty on ca. $95 \%$ of the simulated area (Fig. 2e).

\subsection{Uncertainty in the time series of crop yield}

This section analyses the coincidence of means and variability of time series of yield as an uncertainty indicator resulting from differences in climatic projections from the RCMs and the sensitivity of the crop models to them.

\subsubsection{Comparison of means of time series}

The degree of coincidence, measured as the coincidence among different RCMs in the mean yield, could be evaluated by clustering projections according to scenarios, location and cropping options, in order to obtain rankings of contribution to uncertainty.

All projections within each scenario (Tables 3 \& 5): The degree of coincidence in yield means was ca. $39 \%$, ranging from $7 \%$ (rainfed spring wheat-control in the north-west) to $84 \%$ (maize-control in NE-Valley) considering all projections.
Location: When the degree of coincidence was decomposed by location and averaged over different cropping options, the range obtained was between $30 \%$ (NW-Coast and NE) and 50\% (southern plateau; Table 5).

Scenario $\times$ Cropping option: When the degree of coincidence was averaged over different locations, for each scenario (Table 5), the projections with minimum and maximum uncertainty were maize-control and irrigated spring wheat-control, respectively.

From these results, 3 regions were identified for minimum uncertainty: north-west (Galicia) for winter wheat; NE, NE-Valley, N-Plateau and Centre (Madrid) for maize, and areas of the southern plateau (CastillaLa Mancha) for spring wheat (rainfed and irrigated). Nine of 12 locations exhibited their minimum uncertainty for maize.

Two regions of the Iberian Peninsula were identified for maximum uncertainty. Northern regions, for maize and irrigated spring wheat, and the southern regions for irrigated spring wheat under both control and future climate scenarios. Ten of 12 locations showed their maximum uncertainty for irrigated spring wheat.

In summary, maize showed the smallest uncertainty for the northern plateau and the largest for the northwest (Galicia), winter wheat obtained the smallest uncertainty for the northwest (Galicia) and the largest for the north (Navarra) and centre (Madrid). Spring wheat presented the smallest uncertainty for the southern plateau and the largest for northern and coastal regions (NW-Coast and SE-Coast). Simulations for the south (S-Valley-1 and S-Valley-2, Córdoba) revealed that soil type had a minor effect on uncertainty under irrigated regimes, shown by the similar degree of coincidence among projections. For rainfed spring wheat, uncertainty in S-Valley-2 (with the deepest soil) was double that of S-Valley-1. Larger water storage capacity amplifies responses to annual rainfall variability and inter-model variations. The smaller uncertainty for S-Valley-1 reflected projections of crops experiencing water stress in a consistent way throughout the 30 yr simulations.

\subsubsection{Comparison of interannual variability of time} series

Considering all projections, interannual variability ranged between 4 and $120 \%$ (Table 6, mean CV), while the associated uncertainty to this estimation varied from 7 to $227 \%$ (Tables $3 \& 7, \mathrm{CVmax}-\mathrm{CVmin}$ ). Geographically, i.e. spatially, interannual variability and its uncertainty showed parallel results.

Regarding location, the largest values of both variability (Table 6) and uncertainty (Table 7) were found 
Table 5. Uncertainty of yield projections for the control run (C) and the future scenario (A2), measured by the degree of coincidence among projections of each regional climate model (RCM)-scenario-location-cropping option combination. Coincidence was clustered by cropping option for every location

\begin{tabular}{|c|c|c|c|c|c|c|c|c|c|c|c|}
\hline & \multicolumn{2}{|c|}{ Maize } & \multicolumn{2}{|c|}{$\begin{array}{c}\text { Irrigated } \\
\text { spring wheat }\end{array}$} & \multicolumn{2}{|c|}{$\begin{array}{l}\text { Rainfed } \\
\text { spring wheat }\end{array}$} & \multicolumn{2}{|c|}{$\begin{array}{l}\text { Irrigated } \\
\text { winter wheat }\end{array}$} & \multicolumn{2}{|c|}{$\begin{array}{c}\text { Rainfed } \\
\text { winter wheat }\end{array}$} & \multirow{2}{*}{$\begin{array}{c}\text { Mean over } \\
\text { cropping } \\
\text { options } \\
\text { C \& A2 }\end{array}$} \\
\hline & $\mathrm{C}$ & A2 & $\mathrm{C}$ & A2 & $\mathrm{C}$ & $\mathrm{A} 2$ & $\mathrm{C}$ & A2 & $\mathrm{C}$ & $\mathrm{A} 2$ & \\
\hline NW-Coast & 31.0 & 44.0 & 14.0 & 18.0 & 7.0 & 24.0 & 44.0 & 27.0 & 44.0 & 47.0 & 30.0 \\
\hline NW-Inland & 39.0 & 36.0 & 29.0 & 24.0 & 47.0 & 44.0 & 24.0 & 64.0 & 38.0 & 62.0 & 40.7 \\
\hline $\mathrm{NE}$ & 50.0 & 73.0 & 22.0 & 18.0 & 20.0 & 18.0 & 28.0 & 22.0 & 25.0 & 29.0 & 30.5 \\
\hline NE-Valley & 84.0 & 42.0 & 27.0 & 20.0 & 36.0 & 24.0 & 29.0 & 24.0 & 44.0 & 36.0 & 36.6 \\
\hline N-Plateau & 60.0 & 80.0 & 29.0 & 27.0 & 40.0 & 42.0 & 27.0 & 47.0 & 42.0 & 31.0 & 42.5 \\
\hline Centre & 56.0 & 67.0 & 31.0 & 29.0 & 49.0 & 47.0 & 38.0 & 22.0 & 51.0 & 29.0 & 41.9 \\
\hline S-Plateau 1 & 51.0 & 67.0 & 31.0 & 31.0 & 56.0 & 51.0 & & & & & 47.8 \\
\hline S-Plateau 2 & 60.0 & 51.0 & 33.0 & 42.0 & 60.0 & 53.0 & & & & & 49.8 \\
\hline SW-Inland & 58.0 & 71.0 & 22.0 & 29.0 & 42.0 & 42.0 & & & & & 44.0 \\
\hline SE-Coast & 51.0 & 49.0 & 11.0 & 22.0 & 40.0 & 33.0 & & & & & 34.3 \\
\hline S-Valley $1^{\mathrm{a}}$ & 56.0 & 53.0 & 22.0 & 22.0 & 58.0 & 64.0 & & & & & 45.8 \\
\hline S-Valley $2^{\mathrm{a}}$ & 56.0 & 47.0 & 22.0 & 24.0 & 31.0 & 33.0 & & & & & 35.5 \\
\hline Mean & 54.3 & 56.7 & 24.4 & 25.5 & 40.5 & 39.6 & 31.7 & 44.3 & 40.7 & 49.2 & \\
\hline
\end{tabular}

Table 6. Interannual variability of yield projections for the control run (C) and the future scenario (A2), measured by the mean CV indicator. Mean CV values are presented per cropping option for every location; average mean CV values were clustered by cropping option and location. Dark grey (light grey): projections of largest (smallest) interannual variability

\begin{tabular}{|c|c|c|c|c|c|c|c|c|c|c|c|}
\hline \multirow[b]{2}{*}{ 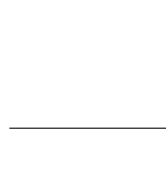 } & \multicolumn{2}{|c|}{ Maize } & \multicolumn{2}{|c|}{$\begin{array}{c}\text { Irrigated } \\
\text { spring wheat }\end{array}$} & \multicolumn{2}{|c|}{$\begin{array}{c}\text { Rainfed } \\
\text { spring wheat }\end{array}$} & \multicolumn{2}{|c|}{$\begin{array}{l}\text { Irrigated } \\
\text { winter wheat }\end{array}$} & \multicolumn{2}{|c|}{$\begin{array}{c}\text { Rainfed } \\
\text { winter wheat }\end{array}$} & \multirow{2}{*}{$\begin{array}{c}\text { Mean over } \\
\text { cropping } \\
\text { options }\end{array}$} \\
\hline & $\mathrm{C}$ & $\mathrm{A} 2$ & $\mathrm{C}$ & $\mathrm{A} 2$ & $\mathrm{C}$ & $\mathrm{A} 2$ & $\mathrm{C}$ & $\mathrm{A} 2$ & $\mathrm{C}$ & $\mathrm{A} 2$ & \\
\hline NW-Coast & 15.1 & 12.3 & 40.2 & 48.8 & 32.3 & 59.5 & 17.0 & 13.0 & 31.5 & 58.6 & 32.8 \\
\hline NW-Inland & 27.2 & 13.2 & 34.7 & 52.2 & 38.4 & 55.1 & 17.3 & 14.0 & 35.6 & 43.0 & 33.1 \\
\hline NE & 31.6 & 16.3 & 17.8 & 30.3 & 36.9 & 30.6 & 11.0 & 9.8 & 30.7 & 26.7 & 24.2 \\
\hline NE-Valley & 16.0 & 19.1 & 11.8 & 15.3 & 53.4 & 42.9 & 6.9 & 7.7 & 65.5 & 80.8 & 32.0 \\
\hline N-Plateau & 17.1 & 15.8 & 10.4 & 21.4 & 53.1 & 41.8 & 8.5 & 9.2 & 68.8 & 70.8 & 31.7 \\
\hline Centre & 9.5 & 14.5 & 11.6 & 17.8 & 84.3 & 73.7 & 7.4 & 9.6 & 98.7 & 120.1 & 44.7 \\
\hline S-Plateau 1 & 9.4 & 14.4 & 11.0 & 17.5 & 56.0 & 52.4 & & & & & 26.8 \\
\hline S-Plateau 2 & 9.3 & 12.1 & 13.4 & 13.3 & 104.8 & 120.4 & & & & & 45.6 \\
\hline SW-Inland & 10.5 & 16.9 & 28.8 & 31.1 & 67.7 & 64.3 & & & & & 36.6 \\
\hline SE-Coast & 8.0 & 10.5 & 19.9 & 20.1 & 87.2 & 83.2 & & & & & 38.2 \\
\hline S-Valley $1^{a}$ & 10.0 & 14.5 & 23.7 & 22.0 & 75.2 & 73.7 & & & & & 36.5 \\
\hline S-Valley $2^{\mathrm{a}}$ & 9.9 & 14.3 & 24.5 & 22.0 & 64.3 & 51.6 & & & & & 31.1 \\
\hline Mean & 14.5 & 14.5 & 20.7 & 26.0 & 62.8 & 62.4 & 11.4 & 10.6 & 55.1 & 66.7 & 45.6 \\
\hline
\end{tabular}

in the north for irrigated crops and in the south for rainfed crops. The opposite was found for the smallest values (both identified in Tables 6 \& 7 ).

Regarding the cropping option scenario, larger values of variability and uncertainty were found for rainfed than for irrigated crops. For irrigated crops, minimum variability and uncertainty were found for maize and maximum for irrigated winter wheat, as was also found for the sign of the response and the comparison of means. The irrigated spring wheat showed large uncertainty in areas (identified in Table 7) of small uncertainty for the other irrigated crops. No control run or A2 scenario showed a clear response for these indicators.

Summarising, minimum uncertainty was obtained for maize in the centre and south and by irrigated winter wheat in the centre and northern plateau, while maximum uncertainty was found for rainfed crops in the north and south and for irrigated spring wheat in the north. 
Table 7. Uncertainty of interannual variability of yield projections for the control run (C) and the future scenario (A2), measured by the (CVmax-CVmin) indicator. (CVmax-CVmin) values are presented per cropping option for every location; mean (CVmax-CVmin) values were clustered by cropping option and location. Dark grey (light grey): projections of largest (smallest) uncertainty; italics: areas of largest uncertainty for irrigated spring wheat

\begin{tabular}{|c|c|c|c|c|c|c|c|c|c|c|c|}
\hline & \multicolumn{2}{|c|}{ Maize } & \multicolumn{2}{|c|}{$\begin{array}{c}\text { Irrigated } \\
\text { spring wheat }\end{array}$} & \multicolumn{2}{|c|}{$\begin{array}{l}\text { Rainfed } \\
\text { spring wheat }\end{array}$} & \multicolumn{2}{|c|}{$\begin{array}{c}\text { Irrigated } \\
\text { winter wheat }\end{array}$} & \multicolumn{2}{|c|}{$\begin{array}{c}\text { Rainfed } \\
\text { winter wheat }\end{array}$} & \multirow{2}{*}{$\begin{array}{c}\begin{array}{c}\text { Mean over } \\
\text { cropping } \\
\text { options }\end{array} \\
\text { C \& A2 }\end{array}$} \\
\hline & $\mathrm{C}$ & A2 & $\mathrm{C}$ & $\mathrm{A} 2$ & $\mathrm{C}$ & A2 & $\mathrm{C}$ & A2 & $\mathrm{C}$ & A2 & \\
\hline NW-Coast & 19.2 & 13.5 & 47.9 & 45.6 & 28.7 & 124.8 & 38.8 & 33.1 & 40.1 & 118.3 & 51.0 \\
\hline NW-Inland & 28.4 & 7.7 & 53.4 & 87.5 & 30.9 & 41.7 & 38.8 & 31.8 & 38.9 & 75.4 & 43.5 \\
\hline NE & 47.8 & 7.6 & 47.6 & 56.7 & 62.0 & 29.2 & 26.3 & 10.8 & 53.5 & 37.4 & 37.9 \\
\hline NE-Valley & 19.6 & 15.5 & 18.9 & 26.2 & 37.2 & 36.6 & 8.4 & 5.0 & 54.2 & 105.1 & 32.7 \\
\hline N-Plateau & 27.1 & 6.8 & 27.0 & 61.3 & 51.5 & 64.1 & 19.2 & 11.4 & 71.0 & 83.9 & 42.3 \\
\hline Centre & 4.3 & 11.3 & 29.6 & 39.0 & 66.7 & 70.9 & 9.1 & 9.5 & 111.4 & 125.3 & 47.7 \\
\hline S-Plateau 1 & 4.8 & 7.3 & 18.6 & 26.4 & 49.8 & 35.1 & & & & & 23.7 \\
\hline S-Plateau 2 & 6.5 & 5.8 & 58.5 & 15.3 & 95.1 & 227.3 & & & & & 68.1 \\
\hline SW-Inland & 5.7 & 10.7 & 58.2 & 48.9 & 84.9 & 46.0 & & & & & 42.4 \\
\hline SE-Coast & 8.2 & 9.1 & 31.8 & 23.5 & 85.0 & 109.9 & & & & & 44.6 \\
\hline S-Valley $1^{\mathrm{a}}$ & 6.5 & 6.8 & 31.7 & 28.2 & 36.7 & 61.3 & & & & & 28.6 \\
\hline S-Valley $2^{\mathrm{a}}$ & 6.5 & 8.6 & 31.4 & 28.6 & 42.1 & 48.0 & & & & & 27.5 \\
\hline Mean & 15.4 & 9.2 & 37.9 & 40.6 & 55.9 & 74.6 & 23.4 & 16.9 & 61.5 & 90.9 & 68.1 \\
\hline
\end{tabular}

\section{DISCUSSION}

\subsection{Response to A2 climate scenarios}

Cropping options that showed the largest differences in response to the control run and the A2 scenario over all locations and RCMs also showed the smallest uncertainty. The reverse was also largely the case. Except for the north (Navarra), projections that showed the least response also showed the largest uncertainty.

The RCM PROMES produced the largest differences between the control run and the A2 impact scenario. Compared to the ensemble mean, PROMES and RegCM climate scenarios produced lower bias for winter temperatures in the Iberian Peninsula (Jacob et al. 2007) from data provided by the Climate Research Unit (CRU) of the University of East Anglia (Hulme et al. 1995) together with ARPEGE for summer temperatures (Jacob et al. 2007). These RCMs were also among those showing the least bias for summer precipitation (Jacob et al. 2007). This comparison illustrates how impact analysis enhances differences among RCMs and therefore uncertainty in their projections and impacts. Multi-model ensembles focus on the uncertainty resulting from structural differences in the climate models, their initial conditions and parameterisations (Semenov \& Stratonovitch 2010). According to the ranges obtained when clustering the results, the primary factor influencing responses to A2 and uncertainty is cropping option, followed by location and finally the RCM.

\subsection{Uncertainty in the sign of the crop yield response}

Two main components of crop response to A2 have previously been identified for the Iberian Peninsula and Mediterranean regions: (1) shortening of the crop duration due to temperature increase (Guereña et al. 2001, Peñuelas et al. 2002); and (2) increased duration of the water deficit during late spring-early summer to late summer-early autumn (Beniston et al. 2007). These responses were confirmed with low uncertainty in the cropping options analysed here (results not shown), and are in agreement with the uncertainty assigned by Iglesias et al. (2009). These components differently affected the sign of the yield response that was projected with low uncertainty in 3 out of 5 cropping options. This can be explained as follows.

All crops were affected by shortening of the crop cycle. For summer crops, represented here by irrigated maize, shortening resulted in a general yield decrease that was projected with low uncertainty. This agrees with climate uncertainty analyses which have shown that temperature and precipitation projected by the PRUDENCE ensemble presented a lower bias in summer than in winter with respect to the CRU database (Jacob et al. 2007).

Winter cropping options, represented here by winter and spring wheat, differed in their response and uncertainty. The difference arose not only from vernalisation requirements, but also to the early sowing dates chosen for winter wheat simulations, as is cur- 
rently done in farms. Low uncertainty was found in the yield increase of winter wheat under irrigation. This increase is a consequence of the $\mathrm{CO}_{2}$ effect and milder temperatures in winter that cause faster crop growth and development rates that are currently limited by minimum temperatures (Díaz-Ambrona \& Mínguez 2001, for barley). Despite the impact of the shorter season length, the yield of winter wheat increased, thus identifying a strong positive response to increased $\left[\mathrm{CO}_{2}\right]$. Winter wheat is not currently sown in the southern Iberian Peninsula due to vernalisation, so it should not be used for describing impacts of climate change in most Mediterranean areas (Olesen 2008; EC JRC IPTS: http://peseta.jrc.ec.europa. eu/). Winter wheat cultivars currently have a longer crop duration than spring cultivars, and when irrigated, precipitation disappears as a source of uncertainty in the simulations. Irrigation thus isolated the effect of $\mathrm{CO}_{2}$ and milder winter temperatures that compensated for the shortening of the growing season. Irrigated spring wheat is sown later in autumn and has a shorter cycle, so that all of these interactions are less clear.

The effect of extended duration of the current water deficit period could be analysed through rainfed crops (winter and spring wheat), which are also influenced by shortening of the crop cycle. Water stress determined the winter wheat response under rainfed conditions. The dominant sign of projections was positive with medium uncertainty, as the increase in water use efficiency (WUE) related to [CO2] (Gifford 1979, Sionit et al. 1981, Tubiello \& Rosenzweig 1995, Easterling et al. 2007) could have been enhanced by the increase in minimum temperatures. Yield decreases would dominate at the centre of the Iberian Peninsula, and a gradient of increasing uncertainty was found from northnorth-west to south-south-east, similar to the current gradient in precipitation (Font Tullot 2000, Ninyerola et al. 2007). This was probably due to the extension of the water deficit period until early autumn expanding southwards.

Spring wheat is currently sown in November to December following the autumn rains, after the water deficit period. Simulations showed how rainfed spring wheat benefited from higher winter temperatures and $\left[\mathrm{CO}_{2}\right]$, such that the small variation of winter precipitation projected by the PRUDENCE ensemble (Déqué et al. 2007) maintained or increase yield with very low uncertainty. In the north-west (Galicia), with an Atlantic climate, differences in current seasonal mean temperatures are ca. half of those found in central Spain, and precipitation is twice that received elsewhere. Improvement in crop WUE under the future climate is not as significant as illustrated by the similarity of uncertainty in results for both rainfed and irrigated spring wheat for the north-west, pointing to a weak water stress in rainfed spring wheat.

\subsection{Uncertainty in the time series of crop yield}

The magnitude of change was subject to much larger uncertainty than the sign of the response, since coincidence in the time series for all locations and crops showed uncertainty close to or below $50 \%$. Inland regions exhibited lower uncertainty than coastal regions. Two locations situated in flat terrain of the southern plateau comprised the region of minimum uncertainty, followed by the rest of the locations in both plateaus. The northern and coastal regions, and locations close to mountains such as the NE (Navarra), were generally identified as maximum uncertainty areas. Jacob et al. (2007) showed that biases of projections with respect to CRU for the Iberian Peninsula climate decreased with the RCMs' resolution. Our results show the need for even higher-resolution simulations to deal with areas with a high altitude gradient or oceanic influence.

Smaller uncertainty in the decrease projected for maize yields compared to the other cropping options in the centre and south is attributed not only to impact on the sign of the response but also to the magnitude of change. Irrigated spring wheat showed the largest uncertainty; the other cropping options presented an intermediate range of uncertainty that differed locally. Irrigation was not able to reduce uncertainty in spring wheat when comparing simulations run with the same soil type, as was also found for the sign of the response. Soil type, and more specifically, soil water storage capacity, had a strong influence on uncertainty under the rainfed regime. In general, the uncertainty linked to the A2 scenario was smaller than that for the control run. This may be due to the dominant effect of increased temperatures over other climate processes, since temperature projections in general have smaller uncertainty than other climate variables such as precipitation (Randall et al. 2007), which exhibits both high natural and model internal variability (Gaertner et al. 2001).

Larger interannual variability of the $30 \mathrm{yr}$ time series was associated with greater uncertainty generated by the RCMs linked to its estimation. Both were much larger than the values found in previous studies based on means instead of time series (Guereña et al. 2001, Mínguez et al. 2007). The range of the uncertainty of interannual variability was wider than the uncertainty of means. The uncertainty level was similar for both the control run and the A2 scenario, and water availability was the main factor that determined it. Irrigation also highlighted the different north-south re- 
sponse. This points to the main role of precipitation in the uncertainty of interannual variability.

\subsection{Consequences of uncertainty evaluation}

Uncertainty levels characterise the relative impact of the projections obtained in this work and that of Mínguez et al. $(2004,2007)$ and establish their validity and utility. Adaptation strategies can be designed for projections of low uncertainty because the problem is clearly identified for negative impacts as is the advantage in situations where crops can gain from future conditions (for positive impacts). Projections of high uncertainty, by contrast, highlight situations where further research is needed to reduce uncertainty before adaptations can be designed. Uncertainty can be reduced by improvement of both climate and impact models (Semenov \& Stratonovitch 2010). These results also question general studies using aggregated crop yield (Iglesias et al. 2009) that predicted reduced yield reduction for Southern Europe.

The ranking of uncertainty shown by Déqué et al. (2007) presented the driving AOGCM as the first factor explaining variance, with some regional variations, followed by the SRES-IPCC scenario and RCM. They showed that in the case of the Iberian Peninsula, the variation introduced by the driving model in precipitation was similar to that generated by the RCM. Also, Cai et al. (2009) pointed out the emission scenario as a main uncertainty source, and when uncertainties are considered together, the different sources can be offset, which would explain part of our results with low uncertainty. The uncertainty introduced by the scenario was not addressed in the present study, and the driving AOGCM was only partially tested by including 2 projections with different drivers. None of them showed further consistent differences with regard to the rest of the ensemble members, and there is therefore a need for a specific experiment focused on this uncertainty source in the peninsula. The ENSEMBLES European project is providing the data needed to perform such an experiment. The ranges of uncertainty obtained when clustering results allowed for extending the ranking by Déqué et al. (2007) to impact assessment. Thus, the factors in decreasing order of contribution to uncertainty were cropping option, location and finally RCM. The indicators in decreasing order of uncertainty were the interannual variability of the impact, mean of impact magnitude and sign of response. Therefore, improvement of crop simulations and specifically simulation of variability should have a large influence in reducing uncertainty. Advances could be achieved by increasing the number of crop models and the site-specific calibrations. In addition, these results stress the importance of showing separate projections for different crops to evaluate agricultural impacts, to avoid simplification that masks possibilities for adaptation (such as the use of winter wheat for all Mediterranean areas, or aggregated forecasts of winter and summer crops together, e.g. the PESETA project).

\section{CONCLUSIONS}

In general, a larger response to the A2 scenario resulted in smaller uncertainty and vice versa. Climate and impact ensemble projections implied, with low uncertainty, the shortening of crop duration in A2 due to increases in temperature and length of the water deficit period. Nevertheless, these facts had different consequences depending on cropping options and locations. Overall, the uncertainty linked to A2 impact projections was smaller than that for control projections. Low uncertainty prevailed for the sign of the crop yield response. Yield increase or maintenance was dominant for spring and winter crops (wheat) and a yield decrease was projected for irrigated, summer crops (maize). The different responses point the way for designing adaptations.

Geographically, uncertainty was smaller for southern than for northern regions, smaller for plateau areas and valleys than for mountains, and smaller for inland than coastal areas. Water deficit and topography may have determined this result.

Maize and irrigated spring wheat showed the smallest and the largest uncertainty, respectively. Irrigated summer maize reflected the low uncertainty linked to summer climate projections. Irrigation reduced uncertainty only for winter wheat, while rainfed spring wheat always had smaller uncertainty due to the dominant effect of the water stress.

According to these results, a ranking was obtained in decreasing order of contribution to uncertainty, from cropping option, to location, and finally RCM. Uncertainty was largest for the interannual variability of the impact, followed by mean of impact magnitude and finally, sign of response of crop yield, in decreasing order.

Autumn-sown, rainfed and irrigated spring wheat is recommended as a cropping option for the evaluation of uncertainties in the AOGCM-RCM-cropping option modelling chain in the Iberian Peninsula. Improvements in spring wheat simulations would further diminish uncertainties. Regions with systematically high uncertainty could benefit from higher-resolution simulations along the modelling chain.

Acknowledgements. This work was funded by the CICYT Project AGL2008-00385/AGR and by the 'Viceconsejería de Ciencia y Tecnología' of the 'Junta de Castilla-La Mancha', 
project PAI08-009-4676. We thank colleagues from the climate modelling group of UCLM MOMAC and our colleagues in AgSystems from UPM for discussions on the subject.

\section{LITERATURE CITED}

Ainsworth EA, Long SP (2005) What have we learned from 15 years of free-air $\mathrm{CO}_{2}$ enrichment (FACE)? A meta-analytic review of the responses of photosynthesis, canopy properties and plant production to rising $\mathrm{CO}_{2}$. New Phytol 165: 351-371

Ainsworth EA, Leaky ADB, Ort DR, Long SP (2008) FACE-ing the facts: inconsistencies and interdependence among field, chamber and modelling studies of elevated $\left(\mathrm{CO}_{2}\right)$ impacts on crop yield and food supply. New Phytol 179: $5-9$

Asseng S, Jamieson PD, Kimball B, Pinter P, Sayre K, Bowden JW, Howden SM (2004) Simulated wheat growth affected by rising temperature, increased water deficit and elevated atmospheric $\mathrm{CO}_{2}$. Field Crops Res 85:85-102

Beniston M, Stephenson DB, Christensen O, Ferro C and others (2007) Future extreme events in European climate: an exploration of regional climate model projections. Clim Change 81(S1):71-95

Cai XM, Wang DB, Laurent R (2009) Impact of climate change on crop yield: a case study of rainfed corn in central Illinois. J Appl Meteorol Climatol 48:1868-1881

Carbone GJ, Kiechle W, Locke C, Mearns LO, McDaniel L, Downton MW (2003) Response of soybean and sorghum to varying spatial scales of climate change scenarios in the southeastern United States. Clim Change 60:73-98

Carter TR, Jones RN, Lu X, Bhadwal S and others (2007) New assessment methods and the characterisation of future conditions. In: Parry ML, Canziani OF, Palutikof JP, van der Linden PJ, Hanson CE (eds) Climate change 2007: impacts, adaptation and vulnerability. Contribution of Working Group II to the Fourth Assessment Report of the IPCC. Cambridge University Press, Cambridge, p 133-171

Castro M, Fernández C, Gaertner MA, Gallardo C (1995) Relevance of regional models for analyzing future climate change in the Iberian Peninsula. In: Moreno JM, Oechel WC (eds) Global change and Mediterranean-type ecosystems, 117. Springer, Berlin, p 1-34

Christensen $\mathrm{JH}$, Christensen OB (2007) A summary of the PRUDENCE model projections of changes in European climate during this century. Clim Change 81(S1):7-30

Christensen JH, Hewitson B, Busuioc A, Chen A and others (2007) Regional climate projections. Climate change 2007: the physical science basis. In: Solomon S, Qin D, Manning M, Chen Z, Marquis M, Averyt KB, Tignor M, Miller HL (eds) Contribution of Working Group I to the IPCC Fourth Assessment Report. Cambridge University Press, Cambridge, p 847-940

Déqué M, Rowell D, Lüthi D, Giorgi F and others (2007) An intercomparison of regional climate simulations for Europe: assessing uncertainties in model projections. Clim Change 81(S1):53-70

Díaz-Ambrona CH, Mínguez MI (2001) Cereal-legume rotations in a Mediterranean environment: biomass and yield production. Field Crops Res 70:139-151

Easterling WE, Aggarwal PK, Batima P, Brander KM and others (2007) Food, fibre and forest products. In: Parry ML, Canziani OF, Palutikof JP, van der Linden PJ, Hanson CE (eds) Climate change 2007: impacts, adaptation and vulnerability. Contribution of Working Group II to the Fourth
Assessment Report of the IPCC. Cambridge University Press, Cambridge, p 273-313

Field A (2005) Discovering statistics using SPSS (2nd edn). Sage Publications, London

Font Tullot I (2000) Climatología de España y Portugal. Universidad de Salamanca, Salamanca

Gaertner MA, Christensen OB, Prego JA, Polcher J, Gallardo C, Castro M (2001) The impact of deforestation on the hydrological cycle in the western Mediterranean: an ensemble study with two regional climate models. Clim Dyn 17:857-873

Gibson JK, Kållberg P, Uppala S, Hernandez A, Nomura A, Serrano E (1999) ERA-15 Description, Version 2. Project Report Series, Reading

Gifford RM (1979) Growth and yield of carbon dioxideenriched wheat under water-limited conditions. Aust J Plant Physiol 6:367-378

Giorgi F, Hewitson B, Christensen J, Hulme M and others (2001) Regional climate information: evaluations and projections. In: Houghton JT, Ding Y, Griggs DJ, Noguer M. and others (eds) Climate change 2001: the scientific basis. Contribution of Working Group I to the Third Assessment Report of IPCC. Cambridge University Press, Cambridge, p 739-768

> Guereña A, Ruiz-Ramos M, Diaz-Ambrona CH, Conde JR, Mínguez MI (2001) Assessment of climate change and agriculture in Spain using climate models. Agron J 93:237-249

Hulme M, Conway D, Jones PD, Barrow EM, Jiang T, Turney C (1995) Construction of a 1961-1990 European climatology for climate change modelling and impact applications. Int J Climatol 15:1333-1363

Iglesias A, Mínguez MI (1995) Perspectives for maize production in Spain under climate change. In: Rosenzweig $C_{\text {, }}$ Allen LH Jr, Harper LA, Hollinger SE, Jones JW (eds) Climate change and agriculture: analysis of potential international impacts, Vol 13. American Society of Agronomy, Madison, WI, p 259-273

Iglesias A, Garrote L, Quiroga S, Moneo M (2009) Impacts of climate change in agriculture in Europe. PESETAAgriculture study. Joint Research Centre Institute for Prospective Technological Studies, European Commission, Seville

Jacob D, Barring L, Christensen O, Christensen J and others (2007) An inter-comparison of regional climate models for Europe: model performance in present-day climate. Clim Change 81(S1):31-52

Jamieson PD, Semenov MA, Brooking IR, Francis GS (1998) Sirius: a mechanistic model of wheat response to environmental variation. Eur J Agron 8:161-179

Jones CA, Kiniry JR (1986) CERES-Maize. A simulation model of maize growth and development. Texas A\&M University Press, College Station, TX

Kimball BA, Kobayashi K, Bindi M (2002) Responses of agricultural crops to free-air $\mathrm{CO}_{2}$ enrichment. Adv Agron 77: 293-368

Loomis RS, Connor DJ (1996) Crop ecology: productivity and management in agricultural systems. Reprint with corrections, Cambridge University Press, Cambridge

> López-Cedrón FX, Boote KJ, Ruíz-Nogueira B, Sau F (2005) Testing CERES-Maize versions to estimate maize production in a cool environment. Eur J Agron 23:89-102

Mariscal MJ (1993) Efectos de la fecha de siembra sobre el crecimiento, desarrollo, producción y uso de agua de genotipos de trigo que difieren en necesidades de vernalización. MSc thesis, Universidad de Córdoba

> Mearns LO (2003) Issues in the impacts of climate variability and change on agriculture. Clim Change 60:1-6 
Mearns LO, Giorgi F, Mcdaniel L, Shields C (2003) Climate scenarios for the southeast U.S. based on GCM and regional model simulations. Clim Change 60:7-35

Mínguez MI, Ruiz-Ramos M, Díaz-Ambrona CH, Quemada M (2004) Productivity in agricultural systems under climate change scenarios. Evaluation and adaptation. J Phys 121: 269-281

Mínguez MI, Ruiz-Ramos M, Díaz-Ambrona $\mathrm{CH}$, Quemada M, Sau F (2007) First-order impacts on winter and summer crops assessed with various high-resolution climate models in the Iberian Peninsula. Clim Change 81:343-355

Nakicenovic N, Swart R (eds) (2000) Emissions scenarios. Special Report of the Intergovernmental Panel on Climate Change. Cambridge University Press, Cambridge

Ninyerola M, Pons X, Roure JM (2007) Monthly precipitation mapping of the Iberian Peninsula using spatial interpolation tools implemented in a Geographic Information System. Theor Appl Climatol 89:195-209

Olesen JE (2008) Adaptation strategies for coping with climate change. Keynote talk at 'Multifunctional Agriculture as a Resource for Energy and Environmental Preservation': 10th Congr Eur Soc Agron, Bologna, Italy, 15-19 September. Ital J Agron 3, Forum, Editrice Universitaria Udinese, Udine

Olesen JE, Carter TR, Díaz-Ambrona CH, Fronzek S and others (2007) Uncertainties in projected impacts of climate change on European agriculture and terrestrial ecosystems based on scenarios from regional climate models. Clim Change 81(S1):123-143

Peñuelas J, Filella I, Comas P (2002) Changed plant and animal life cycles from 1952 to 2000 in the Mediterranean region. Glob Change Biol 8:531-544

Quemada M, Cabrera ML, McCracken DV (1997) Nitrogen released from surface-applied cover crop residues: evaluating CERES-N. Agron J 89:723-729

Randall DA, Wood RA, Bony S, Colman R and others (2007) Climate models and their evaluation. In: Solomon S, Qin

Submitted: June 15, 2010; Accepted: September 9, 2010
D, Manning M, Chen Z and others (eds) Climate change 2007: the physical science basis. Contribution of Working Group I to the Fourth Assessment Report of the IPCC. Cambridge University Press, Cambridge, p 589-662

Rebollo J (1993) Calibración y verificación de un modelo de simulación de trigo (Ceres-Wheat) para las condiciones del Valle del Guadalquivir y su aplicación al análisis de estrategias de riego. MSc thesis, Universidad de Córdoba

Ritchie JT, Otter S (1985) Description and performance of CERES-Wheat: a user-oriented wheat yield model. In: Serv NTI (ed) ARS wheat yield project, Vol ARS-38. Springfield, MI, p 159-175

Semenov MA (2007) Development of high-resolution UKCIP02-based climate change scenarios in the UK. Agric Meteorol 144:127-138

Semenov MA, Stratonovitch P (2010) Use of multi-model ensembles from global climate models for assessment of climate change impacts. Clim Res 41:1-14

Sheskin DJ (2004) Handbook of parametric and nonparametric statistical procedures, 3rd edn. Chapman \& Hall/CRC Press, Boca Raton, FL

Sionit N, Strain BR, Hellmers H, Kramer PJ (1981) Effects of atmospheric $\mathrm{CO}_{2}$ concentration and water stress on water relations of wheat. Bot Gaz 142:191

Tsuji GY, Uehara G, Balas S (eds) (1994) DSSAT Version 3. University of Hawaii, Honolulu, HI

Tubiello FN, Ewert F (2002) Simulating the effects of elevated $\mathrm{CO}_{2}$ on crops: approaches and applications for climate change. Eur J Agron 18:57-74

Tubiello FN, Rosenzweig C (1995) Interactions of $\mathrm{CO}_{2}$, temperature and management practices: simulations with a modified version of CERES-Wheat. Agric Syst 49:135-1 52

van Minnen JG, Alcamo J, Haupt W (2000) Deriving and applying response surface diagrams for evaluating climate change impacts on crop production. Clim Change 46:317-338

Proofs received from author(s): October 15, 2010 